\section{O status da escrita no contexto educacional da língua Sakurabiat}

\author{
The status of writing in the \\ educational context of the \\ Sakurabiat language
}

Carla Daniele Nascimento da COSTA (UFPA) carladncosta@hotmail.com Ana Vilacy Moreira GALÚCIO (UFPA) anavilacy@gmail.com

Recebido em: 21 de jan. de 2019. Aceito em: 20 de maio de 2019.
COSTA, Carla Daniele Nascimento da; GALÚCIO, Ana Vilacy Moreira. O status da escrita no contexto educacional da língua Sakurabiat. Entrepalavras, Fortaleza, v. 9, n. 2, p. 415-433, maio-ago/2019.

Resumo: A escrita e suas representações sociais são objetos de estudo de muitas áreas do conhecimento humano. Entre essas diversas áreas inclui-se a linguística, ciência que embasa as discussões apresentadas neste trabalho que tem por objetivo analisar o status da escrita no contexto educacional da língua indígena Sakurabiat. Para tanto, apoiamo-nos nas discussões teóricas sobre escrita, leitura e oralidade apresentadas por Cagliari (1993) e Marcuschi (2001); e refletimos sobre as relações de poder que envolvem a linguagem, e consequentemente suas representações escritas, segundo a perspectiva de Gnerre (1991). Conceitos como atitudes e crenças linguísticas também são discutidos, tendo como aporte teórico o artigo de Botassini (2015). A metodologia utilizada para a realização da pesquisa foi a técnica de coleta de dados, em trabalho de campo, por meio de entrevistas semiestruturadas com três professores da etnia Sakurabiat. Após a transcrição e análise das falas dos professores, verificamos indícios de crenças e atitudes linguísticas relacionadas à modalidade escrita da língua indígena, apontando para a importância que a escrita e seus produtos têm no contexto educacional da língua materna.

Palavras-chave: Escrita. Língua Sakurabiat. Contexto educacional. 
V. 9 (2)

415-433 maio-ago 2019

Abstract: Writing and its social representations are objects of study of many areas of human knowledge. One of these areas is linguistics, the scientific field upon which this work is based. This article aims to analyze the status of writing in the educational context of the Sakurabiat language. For this, we base ourselves on the theoretical approaches about writing, reading, and orality presented by Cagliari (1993) and Marcuschi (2001); and we reflect on the power relations involving language, and consequently its written representations, according to Gnerre's (1991) perspective. Concepts such as attitudes and linguistic beliefs are also discussed, based on Botassini (2015). The methodology used to carry out this research included fieldwork data collection, through semi-structured interviews with three Sakurabiat teachers. After the transcription and analysis of the teachers' statements, we verified evidence of is of beliefs and linguistic attitudes related to the written modality of the indigenous language, which pointed towards the meaning that writing and its products have in the educational context of the mother tongue.

Keywords: Writing. Sakurabiat language. Educational context.

\section{Introdução}

Geralmente os trabalhos relacionados ao estudo da escrita dizem respeito a análises linguísticas de determinados itens lexicais, ou ainda, à história do desenvolvimento dessa técnica de registro de informação. No entanto, este trabalho suscita discussões sobre "as escritas" (alfabéticas e não alfabéticas) apresentando-as como construções sociais dotadas da capacidade de moldar atitudes e crenças linguísticas sobre línguas, e até mesmo, sobre modalidades de uma mesma língua.

A língua Sakurabiat ${ }^{1}$, abordada neste trabalho, compõe a família linguística Tupari - segunda maior família do tronco Tupi - falada no estado de Rondônia (Brasil). A palavra complexa Sakurabiat (significa literalmente "o grupo dos macacos-prego") é utilizada tanto para se referir à autodenominação do povo étnico de origem Tupi, quanto para nomear a língua falada por esse povo. Em termos populacionais, a comunidade Sakurabiat é constituída por aproximadamente 74 pessoas, vivendo na Terra Indígena Rio Mequens em Rondônia, dentre as quais cerca de 12 falam a língua indígena fluentemente. Infelizmente, a língua encontra-se em sério risco de extinção por diversos fatores, um deles diz respeito à quebra na transmissão da língua às gerações mais novas, nas quais podemos observar o predomínio da língua portuguesa como L1².

\footnotetext{
${ }^{1}$ A escolha pela grafia Sakurabiat (com a inicial maiúscula) está pautada na "Convenção para grafia dos nomes tribais" publicada na Revista de Antropologia (1954).

${ }^{2}$ A escolha pelo termo L1 (primeira língua) em detrimento de LM (língua materna) deve-se ao valor afetivo atribuído ao termo 'língua materna' pelos professores Sakurabiat, os quais entendem o termo como "a língua do povo" e não como a primeira língua adquirida quando criança. Para mais discussões sobre os conceitos de L1 e LM, ver Spinassé (2006).
} 
Apesar do estado de perigo em que a língua se encontra, há cerca de quatro anos um grupo de jovens Sakurabiat iniciou um processo de valorização da língua e cultura do povo, propulsionado, principalmente, pela necessidade de ensino da língua na escola indígena e por atividades desenvolvidas durante disciplinas do programa de formação de professores indígenas no nível de magistério, projeto Açaí, realizado pela Secretaria de Educação do Estado de Rondônia (SEDUC-RO).

É a partir desse contexto de resgate linguístico e de ensino escolar da língua que este trabalho propõe investigar, através da fala dos professores Sakurabiat, o status da escrita no contexto educacional da língua/cultura. Para tanto, adotamos como metodologia de trabalho a coleta de dados em campo através de entrevistas semiestruturadas. A análise dos dados foi feita com base nas discussões teóricas a respeito de crenças e atitudes linguísticas, que envolvem ainda o conceito de status como posição hierarquicamente favorável de um objeto social (BOTASSINI, 2015, p. 123).

Este artigo obedecerá a seguinte estruturação: na seção 1 será apresentado um panorama geral da história do desenvolvimento da escrita, incluindo discussões teóricas a respeito das relações entre as modalidades oral e escrita da linguagem e suas relações de poder. Na seção 2 temos a delimitação de um quadro teórico sobre os conceitos de crenças, atitudes linguísticas e status. O trabalho segue com a descrição da metodologia adotada na pesquisa (seção 3) e a discussão dos dados obtidos através das falas dos professores Sakurabiat (seção 4) - que são analisadas segundo a metodologia e os conceitos teóricos tratados nas seções anteriores. Encerrando o trabalho, apontamos algumas considerações sobre os resultados observados e as implicações destes na sociedade Sakurabiat.

\section{História da tradição escrita}

Antes de apresentar a história da tradição escrita, importante delimitar o que vem a ser "escrita". Na nossa sociedade, há quem considere as placas de trânsito, logotipos de empresas e cartazes como sendo formas de escrita, e há quem não concorde com essa ideia. Isso se deve ao fato de as pessoas entenderem "a escrita" de formas diferentes. Para algumas pessoas apenas textos constituídos de letras e parágrafos representam a escrita; de fato, essa talvez seja a sua representação mais conhecida. Porém, a escrita ultrapassa as fronteiras das letras, que inclusive podem variar a depender da cultura escrita em questão. 
V. 9 (2)

$415-433$ maio-ago 2019
Segundo Cagliari (1993) "A escrita, seja ela qual for, tem como objetivo primeiro permitir a leitura" (CAGLIARI, 1993, p. 103). Esta por sua vez consiste na tradução dos símbolos escritos em fala. Todavia, não podemos entender a leitura como a simples técnica de decifração e somatória dos itens linguísticos. A leitura é mais que isso; ela é a busca de contextualização dos elementos linguísticos com os aspectos sociais e culturais que motivaram a escrita por uma determinada pessoa.

Ainda segundo este autor, é preciso se fazer distinção entre desenho e escrita. Apesar de muitos desenhos terem a capacidade de se transformarem em escrita - é o caso de muitas placas de trânsito - e de os desenhos terem sido historicamente o gancho para o desenvolvimento de muitos sistemas de escrita, eles não são necessariamente feitos para que alguém os leia.

A relação desenho e escrita aparece também na história da escrita enquanto técnica de registro de informação. História esta que Cagliari (1993) divide em três grandes fases: a fase pictórica, a ideográfica e a alfabética. Tal divisão não possui o intuito de classificar as fases em uma linha de evolução cronológica, mas caracteriza o desenvolvimento de diferentes escritas até chegarmos aos recursos dos quais dispomos nos dias de hoje.

A fase pictórica - presente desde as inscrições antigas astecas até, mais recentemente, nas histórias em quadrinhos - é a que diz respeito à escrita por meio de pictogramas e desenhos. Os pictogramas consistem na representação simplificada dos objetos da realidade do que, do mundo real, se quer representar. Já a fase ideográfica é caracterizada pela escrita de desenhos especiais (ideogramas), que ao longo do processo de evolução foram perdendo traços significativos das figuras retratadas e tornando-se cada vez mais uma simples convenção de escrita, a fase ideográfica é representada principalmente pelas escritas hieroglífica, sumérica, cretense e a escrita chinesa. A terceira fase apresentada por Cagliari (1993, p. 109) é a fase alfabética, que teve suas origens nos ideogramas; estes, por sua vez, perderam a função ideográfica e passaram a assumir a função da escrita através da representação puramente fonográfica (relação letra-fonema). Os sistemas de base fonética mais representativos ao longo dos tempos são: o semítico, o indiano e o greco-latino. Antes do alfabeto ter a forma que conhecemos hoje em dia, ele passou por inúmeras transformações, uma delas diz respeito à representação fonética das sílabas das palavras, através dos silabários, que consistiam em "conjuntos de sinais específicos para 
representar cada sílaba" (CAGLIARI, 1993, p. 109). Outra transformação foi o acréscimo pelos gregos da representação gráfica das vogais ao sistema de escrita semítico. Foi após essa adaptação que o sistema de escrita alfabética foi criado.

As discussões apresentadas na seção 4 dizem respeito à análise do status que a escrita alfabética da língua Sakurabiat vem ganhando na comunidade. Tradicionalmente considerados povos ágrafos, os grupos indígenas no Brasil começaram a ter sistemas de representação escrita alfabética a partir do contato com os não-indígenas. Sendo assim, este trabalho se propõe a refletir sobre a relação dos Sakurabiat com a representação escrita da língua indígena.

\section{Relações entre escrita e oralidade}

A escrita representa uma das modalidades que uma língua pode vir a apresentar. Isso quer dizer que além da forma oral, ou gestual-visual no caso das línguas de sinais, uma determinada língua pode se manifestar por meio da representação gráfica de sinais, que podem tomar a forma de letras. Nas palavras de Marcuschi (2001):

A escrita seria um modo de produção textual-discursiva para fins comunicativos com certas especificidades materiais e se caracterizaria por sua constituição gráfica, embora envolva também recursos de ordem pictórica e outros. [...] Trata-se de uma modalidade de uso da língua complementar à fala (MARCUSCHI, 2001, p. 26).

Entendemos, contudo, que Marcuschi não relega a escrita a segundo plano em questão de modalidade linguística. O caráter complementar da escrita, atribuído pelo autor, representa o momento de surgimento da escrita no processo de desenvolvimento das línguas. Em outras palavras, é mais comum vermos o surgimento da escrita de uma língua após séculos de uso oral desta, como é o caso de muitas línguas indígenas, do que o contrário: uma língua iniciar com uma representação escrita para só depois ser oralizada ou sinalizada - no caso das línguas de sinais.

Nesse sentido, a língua Sakurabiat é um dos vários casos de surgimento da escrita alfabética como modalidade complementar da língua oral. É só a partir da década de 1990, com os estudos desenvolvidos por Galúcio (1994), e as demandas resultantes do contato com os nãoindígenas, que a língua Sakurabiat ganha uma ortografia que representa de maneira sistemática a fonologia dos três dialetos que a constituem. 
V. 9 (2)

415-433 maio-ago 2019
Escrita e poder

O valor dado à modalidade escrita, em muitas comunidades, diz respeito às crenças e atitudes que se tem sobre a alfabetização. Em comunidades tradicionais e com poucos recursos econômicos - aqui se encaixam muitos povos ameríndios - o conhecimento das letras quase sempre vem associado à possibilidade de ascensão econômica e desenvolvimento social. No entanto, refletir sobre as representações da escrita, principalmente no processo de alfabetização, é uma tarefa necessária quando se busca entender a vida em sociedade e suas representações sóciohistóricas; é partindo dessa motivação que este trabalho busca perceber na fala dos professores indígenas Sakurabiat o status que a escrita possui no atual contexto educacional da língua materna.

Segundo Gnerre (1991) a capacidade de refletir sobre a escrita perpassa por questões sociais que envolvem alfabetizador(es) e alfabetizando(s):

Quando refletirmos sobre a alfabetização devemos pensar que os alfabetizandos, sejam eles crianças ou adultos, são necessariamente membros de grupos étnicos e de classes sociais, assim como os próprios alfabetizadores. Eles compartilham atitudes, crenças, hipóteses sobre a escrita, sua natureza, suas funções e os valores que a ela estão associados, da mesma forma que nós (os alfabetizadores reais ou em termos sócio-históricos) compartilhamos atitudes, crenças, hipóteses sobre a escrita (GNERRE, 1991, p. 45).

As crenças e atitudes linguísticas, tanto dos alfabetizandos quanto dos alfabetizadores, precisam ser levadas em consideração em seus aspectos sociais e ideológicos, pois, se de um lado temos os alfabetizadores - dotados das técnicas e conhecimentos linguísticos para ensinar aos alfabetizando as "letras" -, do outro lado temos a figura dos alfabetizandos - pertencentes a comunidades étnicas diferentes que trazem consigo os conhecimentos e valorações prévias sobre as representações escritas. Logo, estes não devem ser vistos como seres passivos que anseiam pela aquisição da escrita, o que de fato silencia todo o percurso sócio-histórico do desenvolvimento dos programas de alfabetização ao longo do tempo.

A respeito deste assunto, Gnerre (1991, p. 44) nos fala sobre o "mito" da alfabetização - compartilhado tanto por países em desenvolvimento quanto pelos industrializados - que, seguindo uma lógica mercantilista, consiste na representação da alfabetização como um passo necessário e substancial para o processo de "modernização" dos cidadãos. 
Sob essa perspectiva, as grandes massas deveriam abandonar suas culturas centradas na oralidade, classificadas como menos "desenvolvidas", para adentrarem aos espaços mais desenvolvidos tecnologicamente, e assim, contribuírem para o progresso e avanço do Estado.

Sabemos que a relação entre escrita e as dinâmicas econômicas e sociais ditaram, e ditam até hoje, quais línguas ou variedades linguísticas terão sua forma escrita e serão prestigiadas na sociedade. Quanto mais envolvida nas dinâmicas políticas e econômicas, mais facilmente uma língua será associada ao modo "estável" que a escrita representa. Em situações multilíngues, por exemplo, Gnerre (1991) diz que "o passo fundamental na afirmação de uma variedade sobre as outras é sua associação à escrita e, consequentemente, sua transformação em uma variedade usada na transmissão de informações de ordem política e 'cultural'" (GNERRE, 1991, p. 7). O que ocorre é que uma língua ou variedade linguística acaba por incorporar o "poder" que seus falantes exercem na sociedade, como afirma Bourdieu (1977 apud GNERRE, 1991, p. 5) "o poder da palavra é o poder de mobilizar a autoridade acumulada pelo falante e concentrá-la num ato linguístico". Sobre esse assunto, muito nos é esclarecido a partir dos estudos de crenças e atitudes linguísticas, discutidos a seguir, que irão influenciar, consequentemente, as relações de poder entre a escrita e as sociedades tradicionalmente ágrafas, como as comunidades indígenas, a exemplo os Sakurabiat.

\section{Crenças, atitudes linguísticas e status}

Os conceitos de crenças e atitudes aparecem em vários estudos relacionados à área das ciências humanas. Isto torna difícil a tentativa de defini-los, pois, a depender do objeto de estudo em questão, teremos diferentes conceitos de crença e atitude. Para este trabalho, adotamos os conceitos de crenças e atitudes linguísticas a partir das discussões feitas dentro do campo da ciência da linguagem, como a Linguística Aplicada e a Sociolinguística. Posto isto, apresentamos a seguir o conceito de "crença" segundo Barcelos (2007) a partir de uma abordagem da Linguística Aplicada. A autora nos diz que crença é:

[...] uma forma de pensamento, construção da realidade, maneira de ver e perceber o mundo e seus fenômenos, coconstruídas em nossas experiências resultantes de um processo interativo de interpretação e (re)significação. Como tal, crenças são sociais (mas também individuais), dinâmicas, contextuais e paradoxais (BARCELOS, 2007, p. 113). 
V. 9 (2)

415-433 maio-ago 2019
A autora ressalta que sua visão parte da ideia de que as crenças são socialmente construídas e situadas contextualmente, são, portanto, dinâmicas. É a partir da interação que as pessoas modificam suas experiências e também são modificadas por elas. Logo, as crenças "incorporam as perspectivas sociais, pois nascem no contexto da interação e na relação com os grupos sociais" (BARCELOS, 2007, p. 114). A autora também nos fala das características paradoxais e contraditórias das crenças, pois ao mesmo tempo em que são formadas através da socialização de experiências, ou seja, são sociais, elas também são individuais no sentido de que cada ser humano experiencia de maneira única suas vivências. É compartilhando da visão de Barcelos (2007) que as discussões sobre crenças são apresentadas neste trabalho.

Botassini (2015) apresenta o trabalho de Yero (2010) ressaltando a diferenciação que a autora faz entre "fato" e "crença", entendendo esta última como "julgamentos e avaliações que fazemos de nós mesmos, sobre os outros e sobre o mundo que nos rodeia" (YERO, 2010 apud BOTASSINI, 2015, p. 108). Já os fatos, nas palavras de Botassini (2015):

são declarações que fazem parte do consenso da realidade, havendo pouca dúvida sobre sua veracidade; são elementos para os quais existe um corpo enorme de apoio e sem evidências contraditórias, sendo raramente questionados (BOTASSINI, 2015, p. 108).

Destaforma, as crençasestariam na contramão do conhecimento factual, pois elas estariam muito mais voltadas a avaliações motivadas pela emoção, do que por evidências concretas e consensuais. Enquanto o fato é compartilhado por um grupo de indivíduos que possui um consenso de realidade, as crenças - construídas socialmente - são codificadas como características pessoais e afetam o comportamento e a percepção do ambiente em que a pessoa está inserida.

Já os estudos sobre atitudes linguísticas, iniciados na Psicologia Social, tiveram como propulsor o interesse em se estudar os aspectos sociais, ideológicos e culturais da linguagem. Foi a partir da publicação do artigo A social Psychology of Bilingualism, de Wallace Lambert (1967), que os estudos acerca das atitudes linguísticas ganharam uma metodologia própria de investigação através da técnica matched guise - conhecida em português como "falsos pares" - que tem como propósito inferir e medir atitudes. Segundo Labov (2008 apud BOTASSINI, 2015, p. 112), tal técnica "trouxe um progresso considerável na mensuração das reações 
sociais inconscientes à linguagem e proporcionou uma metodologia segura e uma série de princípios empíricos para o estudo das reações subjetivas". Portanto, o estudo sobre "atitudes linguísticas", a partir do final da década de 1960, passa a ser de interesse também da ciência da linguagem, principalmente, da Sociolinguística haja vista o interesse em investigar as línguas e dialetos em contato.

Há duas grandes linhas de pesquisa sobre "atitudes linguísticas": uma denominada mentalista e a outra comportamentalista. A primeira, segundo Moreno Fernández (1998), compreende atitudes como "[...] estado interno do indivíduo [...] uma categoria intermediária entre um estímulo e o comportamento ou a ação individual" (MORENO FERNÁNDEZ, 1998, p. 182). Nessa perspectiva, as atitudes linguísticas constituem estruturas múltiplas complexas compostas por três elementos: o cognitivo (relativo às crenças); o afetivo (sentimentos e valoração) e o conativo (condutas e comportamentos sociolinguísticos). Já para a visão comportamentalista, a atitude é uma unidade indivisível composta apenas pelo componente conativo, referente ao comportamento.

Neste trabalho, adotamos a visão mentalista das atitudes linguísticas, por esta ter caráter preditivo e por entender que determinadas atitudes, como as que desencadeiam o preconceito linguístico, por exemplo, podem ser entendidas como resultado de crenças que subjugam grupos étnicos e, por conseguinte, a língua, ou as línguas, que falam. Sobre isso, Moreno Fernández (1998) nos diz que "a atitude linguística é uma manifestação da atitude social dos indivíduos, distinguida por centrar-se e referir-se especificamente tanto à língua como ao uso que dela se faz em sociedade" (MORENO FERNÁNDEZ, 1998, p. 180).

Outro conceito importante para o desenvolvimento desta pesquisa é o referente a status, que em seu sentido lato não carrega caráter positivo, podendo ser entendido como "situação, estado ou condição de alguém ou algo, perante a opinião das pessoas ou em função do grupo ou categoria em que é classificado" (FERREIRA, 2009 apud BOTASSINI, 2015, p. 123). Todavia, o sentido adotado nesta pesquisa é o de status como sinônimo de prestígio, que segundo a Antropologia Social refere-se ao "grau de distinção ou de prestígio, ou a situação hierárquica de um indivíduo ou grupo de indivíduos perante os demais membros de seu grupo social" (BOTASSINI, 2015, p. 123). Assim como podemos ter grupos sociais providos de determinado status, podemos também ter o caráter prestigioso, ou seja, a atribuição de status elevado 
v. 9 (2)

415-433 maio-ago 2019

aos artefatos sociais construídos pelos grupos sociais, como pode ser entendida a construção da tradição escrita nas sociedades em que esta técnica se faz presente.

\section{Metodologia}

A coleta de dados para esta pesquisa foi realizada pela primeira autora na cidade de Presidente Médici (RO) durante o IX módulo do curso de formação de professores indígenas pelo projeto Açaí, já mencionado anteriormente. Participaram da entrevista três professores indígenas (duas mulheres e um homem) que estão à frente das ações de ensino-aprendizagem da língua e cultura do povo Sakurabiat ${ }^{3}$. O roteiro da entrevista foi, em parte, elaborado pela entrevistadora e, em parte, adaptado do questionário utilizado por Francês Júnior (2014).

Ao todo, o questionário que orientou a entrevista semiestruturada possui 42 perguntas que englobam desde o grau de conhecimento linguístico que os professores têm da língua indígena, até questões relacionadas às expectativas de ensino-aprendizagem das modalidades oral e escrita da língua. Porém, para este trabalho, utilizamos apenas seis perguntas relacionadas ao ensino-aprendizagem da modalidade escrita de Sakurabiat.

As entrevistas ocorreram ao longo de três dias e foram realizadas individualmente com cada professor. A metodologia empregada permitiu a adequação das perguntas durante a entrevista, e até mesmo o acréscimo de novas, conforme a necessidade apresentada no momento da coleta de dados. As respostas dos entrevistados foram registradas em áudio através de gravador Olympus LS-10 e através de anotações escritas. Foi acordado no momento da entrevista e registrado através de termo de consentimento livre e esclarecido, assinado pelos participantes da pesquisa, que os dados coletados em campo poderiam ser usados para compor trabalhos acadêmicos e publicados desde que a identidade dos participantes fosse preservada através da elaboração de códigos que substituíssem os dados pessoais dos professores, como nome, idade e comunidade de origem.

Portanto, foi elaborada uma estrutura de codificação constituída por seis caracteres: as três primeiras letras dizem respeito à abreviação do nome de cada professor, seguidas pela idade, sexo ( $M$ para masculino e F para feminino) e a(s) inicial(is) do nome da comunidade, em letra

${ }^{3}$ A pesquisa teve anuência dos caciques das comunidades Sakurabiat, em documento escrito. 
minúscula. A partir disso foram gerados os códigos: AMS21Ms, AGS32Fk e SSG31Fbv que correspondem a cada um dos professores e que serão utilizados ao longo do trabalho para fazer referência aos entrevistados.

Após a coleta de dados foram feitas as devidas transcrições das entrevistas realizadas com cada professor. Na seção a seguir serão apresentados fragmentos dessas entrevistas para efeito de materialização linguística da fala dos professores.

\section{A Escrita no contexto educacional da língua Sakurabiat}

A situação sociolinguística dos Sakurabiat reflete um quadro de vulnerabilidade quanto à manutenção e vitalidade da língua tradicional. Todos os 74 Sakurabiat, que vivem na Terra Indígena (T.I.) Rio Mequens, são fluentes em Português. Há somente $13^{4}$ falantes fluentes de Sakurabiat, a maioria acima de 50 anos de idade, e 07 falantes passivos, que compreendem uma sentença, mas não conseguem responder ou estabelecer um diálogo na língua. O restante do grupo conhece somente palavras, especialmente do vocabulário de fauna e flora e itens específicos do uso cotidiano e relações próximas de parentesco. A transmissão da língua está interrompida há mais de duas décadas; Português é a primeira e única língua das crianças nascidas na T.I. desde então.

Antes de discutir o papel da escrita no contexto educacional da língua Sakurabiat, é importante historiar o sistema de escrita dessa língua indígena e os materiais disponíveis. Até o final da década de 1990 não havia um sistema de escrita para a língua Sakurabiat. Tal sistema foi elaborado por Galúcio, no âmbito de um projeto de alfabetização de adultos, realizado entre 1996 e 1998, com o apoio do Museu Paraense Emilio Goeldi e da Fundação Norueguesa para a Floresta Tropical. Nesse período, cinco adultos foram alfabetizados em Sakurabiat. O sistema ortográfico Sakurabiat, aprovado em reuniões com a presença de todos os membros adultos da comunidade à época de sua elaboração, segue uma orientação fonológica na representação gráfica e apresenta a equivalência uma-a-um entre fonemas e grafemas. Existem somente duas obras escritas em Sakurabiat. Uma cartilha de apoio à alfabetização na língua Sakurabiat (GALÚCIO e FERREIRA SAQUIRABIAR, 2004) e uma coletânea bilíngue reunindo 25 histórias tradicionais Sakurabiat,

${ }^{4} 12$ falantes fluentes que moram na Terra Indígena Rio Mequens, e 1 falante que mora atualmente na Terra Indígena Rio Branco, também no estado de Rondônia. 
v. 9 (2)

415-433 maio-ago 2019

escritas na língua indígena e em português, acompanhadas da narrativa oral em Sakurabiat (GALÚCIO, 2006). Ambos os materiais são de acesso livre a toda a comunidade e são utilizados em maior ou menor escala.

Posto isto, apresentamos a seguir a análise das entrevistas com os professores sobre o papel da escrita no contexto educacional da língua Sakurabiat. Para cada pergunta temos as transcrições das respostas dos três professores entrevistados, identificados através de um código, como descrito na seção anterior, seguidas das suas respectivas análises:

\section{- Você sabe ler e escrever em Sakurabiat 5 ?}

\begin{tabular}{|ll}
\hline Resposta de AMS21Ms & Não. \\
Resposta de AGS32Fk & Não. \\
Resposta de SSG31Fbv & Escrever eu não sei muito não porque tem muitas \\
& palavras que eu não entendo muito das letras, porque \\
& é como a gente fala: lê de um jeito e escreve de \\
& outro. Então, eu não escrevo muito, não. Mas assim, \\
& pouca coisa, eu escrevo.
\end{tabular}

Seguindo a possibilidade de adequação das perguntas, e até mesmo o acréscimo de novas, dada a necessidade apresentada no momento da coleta de dados, a professora SSG31Fbv foi questionada sobre quando ela havia começado a tentar ler em Sakurabiat. Sua resposta foi que começou a ler quando ganhou um livro de narrativas bilíngue (Sakurabiat-português). Ela disse que como já tinha uma "base" da escrita em português, começou a tentar ler em Sakurabiat sozinha, lendo o livro de narrativas primeiro na língua indígena e depois em português. Ela também disse que quando começou a trabalhar na escola como professora, se interessou mais em aprender a ler e escrever em Sakurabiat para que pudesse ensinar a língua aos alunos; além disso, a professora disse que costuma ler o livro de narrativas para as crianças na escola.

\footnotetext{
5 Se a resposta a essa pergunta fosse "sim", a próxima pergunta da entrevista seria "quando e com quem você aprendeu?".
} 
- Se não, você gostaria de aprender a ler e escrever em Sakurabiat?

\begin{tabular}{|ll|}
\hline Resposta de AMS21Ms & Sim. \\
Resposta de AGS32Fk & Sim. \\
Resposta de SSG31Fbv & $\begin{array}{l}\text { Eu gostaria de aprender a escrever bem escrito e de } \\
\text { falar bem também. Gostaria de aprender para falar e } \\
\text { escrever, para estar falando e escrevendo as palavras } \\
\text { certinho. }\end{array}$ \\
\hline
\end{tabular}

Quando questionados sobre aprender a ler e escrever em Sakurabiat, todos os professores manifestaram interesse na aquisição da modalidade escrita da língua indígena. Como a professora SSG31Fbv havia dito na pergunta anterior que não sabia ler e escrever bem, mas que tentava, a pergunta feita para ela foi se gostaria de aprender a ler e escrever mais, e a resposta foi a transcrita acima, que explicita o interesse da professora em aprender a ler e escrever "bem", além do interesse de aprender a falar.

Vale ressaltar que nenhum dos três professores sabe falar fluentemente a língua indígena. O grau de conhecimento linguístico entre eles varia muito, indo do conhecimento de algumas palavras até o reconhecimento de frases com palavras utilizadas no dia a dia, como nomes de frutas e animais. Apesar disso, nenhum deles consegue, por exemplo, manter uma conversa com os mais velhos (falantes fluentes da língua). Daí o interesse e a valorização da modalidade escrita da língua Sakurabiat, já que o ensino oral da língua indígena foi interrompido devido a diversos fatores, como a imposição do português, seja pela força física - no período dos barracões para a coleta do látex os Sakurabiat foram proibidos de falar a língua indígena e sofriam violência física quando o faziam - seja pela força simbólica - devido à necessidade de falar português como meio de sobrevivência. 
V. 9 (2)

415-433 maio-ago 2019

\begin{tabular}{|cl|}
\hline Se sim, por quê? & \\
\hline Resposta de AMS21Ms & É muito interessante que tem as histórias que a \\
& professora V. trouxe, que tem na língua materna e \\
& na língua portuguesa. E eu só consigo ler na língua \\
& portuguesa, na língua materna eu (quase) não \\
& consigo. Mas eu já tentei com a minha mãe, ela vai \\
& explicando, vai falando. Ler para as crianças também \\
& é muito interessante. Eu sabendo dominar a língua \\
& Sakurabiat ficaria mais fácil para ensinar as crianças. \\
& A importância que eu vejo é ir atrás da minha \\
& origem, é saber.... É essa importância que eu vejo, \\
& e de alguma maneira ajudar alguém dentro da \\
& comunidade. Por isso que eu acho que é importante \\
Resposta de AGS32Fk & para mim e é uma coisa que não irei desistir fácil. \\
& Então, é por isso que eu sei que isso (a escrita), de \\
& alguma maneira, vai me servir mais tarde. \\
& Eu vejo assim, a importância de (aprender a) \\
& escrever e falar é porque você já não perderia a \\
& língua materna. E escrever, você vai escrevendo e \\
& guardando para as crianças que vem nascendo agora, \\
& você vai registrando. \\
\hline Resposta de SSG31Fbv &
\end{tabular}

Com a quebra na transmissão da língua oral, muitos conhecimentos culturais acabam não sendo repassados para as crianças, um desses conhecimentos são as estórias tradicionalmente contadas oralmente. Conseguir acessar essas informações culturais por meio da escrita é uma das motivações que o professor AMS21Ms aponta para aprender a ler e escrever na língua indígena. Além disso, há a necessidade e o interesse no aprendizado da língua escrita para ensinar essa modalidade para as crianças.

A vontade de repassar as estórias, e com elas os conhecimentos tradicionais sobre o povo, também é apontada pela professora SSG31Fbv que vê na escrita uma forma de documentação - registro, como ela fala - da língua materna de seu povo. Podemos perceber através da fala desta professora a crença de que a escrita tem a capacidade de guardar a língua materna. E a partir dessa crença, compartilhada socialmente pelos professores, temos uma atitude linguística positiva frente ao ensino-aprendizagem da escrita Sakurabiat. Tal atitude evidencia o prestígio da escrita na nossa sociedade não-indígena, que está sendo refletido - atualmente - no contexto educacional da língua Sakurabiat.

A possibilidade de registrar conhecimentos através da escrita é uma das formas que muitos povos possuem para documentar fatos e informações importantes, podendo acessá-los ao longo do tempo para (re)lembrar tais informações. Nesse sentido, a atitude expressa pelos 
professores, em querer aprender e ensinar a escrita Sakurabiat pode ser entendida como um dos meios pelos quais eles buscam valorizar a língua materna. Se antes, quando a língua e a cultura Sakurabiat eram repassadas oralmente para as gerações mais novas, a escrita era inexistente, portanto, não tinha nenhuma função social para os Sakurabiat; hoje, no atual contexto de vulnerabilidade da língua, a escrita ocupa um papel importante na documentação dos conhecimentos tradicionais do grupo, adquirindo status elevado no contexto educacional da língua Sakurabiat.

A professora AGS32Fk diz que a importância em saber ler e escrever em Sakurabiat está relacionada com a possibilidade de aprender mais sobre sua origem e que a escrita vai auxiliá-la no futuro. Tal crença reflete a importância dada à escrita pelos três professores nesse momento de resgate linguístico, incentivado, também, pelas discussões promovidas durante o curso de formação de professores indígenas. Nesse curso os alunos interagem com professores indígenas e não-indígenas que têm crenças e atitudes sobre a escrita. É a partir dessa interação que os professores Sakurabiat constroem suas próprias crenças referentes à modalidade escrita das línguas, em específico à escrita Sakurabiat.

- Onde você acha que poderia aprender a ler e escrever em Sakurabiat?

\begin{tabular}{|ll|}
\hline Resposta de AMS21Ms & Ler, eu posso até conseguir em casa mesmo por \\
& conta do livro didático. Agora escrever eu não tenho \\
& ideia. \\
Resposta de AGS32Fk & No momento eu não vejo onde conseguir aprender a \\
& escrever e a ler. Falar, tem até gente que fala, agora \\
& escrever já é mais complicado porque a gente fica ali \\
& tentando juntar (as letras) mas a gente sabe que não \\
& é "o original". A gente fica tentando adivinhar os \\
& sons, mas a gente sabe que não é bem assim. Agora \\
& eu não vejo nenhum local, a não ser esses métodos \\
& de ir atrás, como ajudar, uma linguista ajudar a \\
& gente, porque para falar é mais fácil porque tem \\
& gente (que fala); agora escrever é mais complicado. \\
& Acho assim, que em casa eu aprendo lendo, né? \\
& Mas acho que na escola a gente escrevendo a gente \\
& aprende mais ainda porque você está vendo como \\
& escreve, como fala. Agora em casa só lê e fala, mas \\
nesposabe como escreve. Agora (se tivesse) uma & professora ensinando como que fala e escreve a gente \\
& ia aprender mais. \\
\hline
\end{tabular}


V. 9 (2)

415-433 maio-ago 2019
Como podemos ver nas respostas acima, para os dois primeiros professores não há atualmente na comunidade Sakurabiat um lugar onde se possa ir para aprender a ler e escrever na língua indígena. $\mathrm{Na}$ fala deles, a coletânea bilíngue de textos tradicionais (GALÚCIO, 2006) aparece como ferramenta mediadora que pode auxiliar na atividade da leitura em casa, o que - segundo eles - não ocorre para o aprendizado da escrita. Já para a professora SSG31Fbv, além da possibilidade de ler em casa, a escola é o lugar de aprendizagem da escrita, onde se pode ter a oportunidade - como ela mesma coloca - de ver como se escreve e como se fala. É importante frisar, também, que SSG31Fbv é a única professora contratada pela SEDUC-RO, e desempenha a função de professora na escola de sua comunidade, que atualmente é a única escola indígena Sakurabiat em atividade. Dessa experiência, talvez, venha a sua visão diferenciada em perceber a escola como um espaço formal dedicado ao ensino-aprendizagem da leitura e da escrita na língua indígena.

Além disso, a figura do linguista ou professor, ou seja, de alguém dotado dos conhecimentos linguísticos necessários para o ensino da leitura e da escrita, aparece na fala das duas últimas professoras, que evidenciam o poder exercido por aqueles que têm o domínio da técnica da escrita, mesmo que estes não sejam falantes fluentes da língua indígena. Fica evidente o poder de grupos sociais (professores e linguistas não-indígenas) que é refletido na linguagem, sobretudo, no domínio da modalidade escrita.

- Quem vocêacha que poderia lhe ensinar a ler e escrever em Sakurabiat?

\begin{tabular}{|c|c|}
\hline Resposta de AMS21Ms & $\begin{array}{l}\text { Não consigo pensar em ninguém. É muito a questão } \\
\text { da dificuldade de ter alguém lá para ensinar a gente } \\
\text { a ler e escrever. }\end{array}$ \\
\hline Resposta de AGS32Fk & $\begin{array}{l}\text { É complicado porque o pessoal sabe falar, mas não } \\
\text { sabe escrever. Eu optaria por esse método de buscar, } \\
\text { de estudar mais os sons, os sinais. Alguma coisa } \\
\text { assim, porque dentro da comunidade alguém que } \\
\text { saiba falar e escrever é difícil. }\end{array}$ \\
\hline Resposta de SSG31Fbv & $\begin{array}{l}\text { Indígena mesmo não tem porque meu pai não sabe } \\
\text { escrever, meus tios também não, eles sabem falar, } \\
\text { mas não (sabem) escrever. Tinha que ser um não } \\
\text { indígena para nos ensinar a escrever porque eles } \\
\text { já sabem as letras tudinho. Agora se tivesse um } \\
\text { (indígena) que soubesse escrever as letras tudo } \\
\text { certinho, a gente aprenderia bem mesmo. }\end{array}$ \\
\hline
\end{tabular}


Como as professoras AGS32Fk e SSG31Fbv pontuam, há pessoas nas comunidades que falam a língua e que poderiam ensinar a falar, mas essas pessoas não sabem escrever. Daí a necessidade de alguém "de fora", geralmente não-indígena, para auxiliá-los na aquisição dessas práticas (leitura e escrita) que - ao contrário do que nossa sociedade grafocêntrica pode fazer parecer - não são intrínsecas às línguas naturais.

Interessante ressaltar, na fala da professora SSG31Fbv, o valor positivo que seria ter um indígena que soubesse ler e escrever, e assim ensinar seus pares tais processos. Nesse exemplo, teríamos uma alfabetização significativa do ponto de vista das crenças e das atitudes linguísticas da comunidade, já que o indígena - além das capacidades técnicas - levaria consigo para a escola as demandas de leitura e de escrita próprias de seu povo.

- Você gostaria que alguém que você conhece (filho, sobrinho, irmão etc.) aprendesse a ler e a escrever em Sakurabiat? Se sim, por quê?

\begin{tabular}{|ll|}
\hline Resposta de AMS21Ms & Gostaria bastante porque a gente foca mais na questão \\
& do material. Tendo um material a gente consegue ter \\
& um planejamento de como vamos planejar para as \\
& crianças pequenas "pegar" (a escrita) mais rápido. \\
& É muito importante, principalmente, as crianças \\
& aprenderem a dominar a língua materna. \\
& Sim, porque eu sempre volto a esse tema de \\
& não perder a valorização. Para mim seria muito \\
& importante porque futuramente a gente saberia de \\
& onde viemos, quem fomos, apesar de ter envolvido \\
& já uma grande globalização. E eu acho que ajudaria \\
& a abrir meios para ajudar não só o nosso povo e a \\
& comunidade, mas no geral. A gente sabe que com os \\
& governos que temos, necessitamos muito de união e \\
& de não ter vergonha de mostrar quem somos. \\
& Tem os meus irmãos. Tem um de 18, um de 15 e tem um \\
& de 12. Eu gostaria que eles aprendessem a ler e escrever, \\
& a falar também. E principalmente o meu filho que já \\
& está grande, que não sabe falar. Ele está aprendendo o \\
português, mas não sabe a língua materna. Eu gostaria & \\
muito de ver eles falando e escrevendo.
\end{tabular}

A importância em aprender a ler e a escrever em Sakurabiat não se restringe aos professores. Eles demonstram atitudes positivas frente à escrita e à leitura também em relação às outras pessoas da comunidade, principalmente às crianças. Aprender a ler e escrever em Sakurabiat, para os professores, significa dominar e valorizar a língua 
V. 9 (2)

$415-433$ maio-ago 2019

materna e a cultura, e assim preservar os conhecimentos tradicionais para, como diz a professora AGS32Fk: "saber de onde vieram".

A importância do bilinguismo aparece na fala de SSG31Fbv ao mencionar seus irmãos e filho, que usam mais o português do que a língua materna. A educação escolar bilíngue é um dos pilares da educação escolar indígena. Ainda assim, são poucas as escolas indígenas que conseguem implantar tal educação devido a não fluência dos professores em suas línguas maternas, como é o caso dos Sakurabiat. Uma das alternativas apontadas pelos próprios indígenas é iniciar tal educação através da escrita, que como afirma o professor AMS21Ms carece de planejamento de ensino. Tal situação, segundo a visão do professor, poderia ser remediada através da elaboração de materiais didáticos. Sendo assim, a escrita possui status elevado no contexto educacional da língua Sakurabiat; é a partir dela que os professores buscam preservar a língua e a cultura de seu povo.

\section{Considerações finais}

Como pudemos ver através das falas dos professores, a escrita tem um papel importante no contexto educacional da língua materna. Ela tem a capacidade de "guardar" os conhecimentos ainda acessíveis da língua e cultura do povo, o que pode auxiliar os indígenas na investida do resgate linguístico e cultural. Sabemos, contudo, que a escrita é apenas uma das modalidades linguísticas existentes, e que não garante a sobrevivência de nenhuma língua.

A atitude positiva frente à escrita, expressa não só pela vontade de aprender a ler e a escrever em Sakurabiat, mas também pelo interesse na elaboração de materiais didáticos para o ensino da língua, parte da crença de que os produtos da escrita, como os livros, têm a capacidade de preservar a língua materna. De fato, ter o recurso do livro didático é uma ferramenta importante para o ensino da língua, haja vista a falta deste recurso em línguas indígenas e/ou para o ensino delas. Entretanto, observamos que o maior desafio do povo Sakurabiat está em transpor o ensino da língua para além das fronteiras da escola, alcançando o seio da comunidade e a volta do repasse da língua oral através das gerações.

Para que isso aconteça, uma atitude positiva sobre o ensino da língua precisa ser compartilhada por todos os membros da comunidade, principalmente pelos mais velhos, detentores da língua materna, que precisam compartilhar com os professores o interesse pela volta da aquisição da língua e a importância do ensino da língua Sakurabiat no contexto 
educacional. Tal mudança de atitude está intimamente relacionada às políticas linguísticas vigentes no país que denotam o poder e as funções que as línguas exercem na sociedade, e que auxiliam nas crenças compartilhadas por comunidades inteiras. Ter políticas eficazes no reconhecimento e valorização de comunidades tradicionais é dar condições para a preservação de tais povos e, consequentemente, de suas línguas e culturas.

\section{Referências}

BARCELOS, A. M. F. Reflexões acerca da mudança de crenças sobre ensino e aprendizagem de línguas. Revista Brasileira de Linguística Aplicada, Belo Horizonte, v. 7, n. 2, p. 109-138, 2007.

BOTASSINI, J. O. M. A importância dos estudos de crenças e atitudes linguísticas para a sociolinguística. Signum, Londrina, n. 18/1, p. 102-131, jun., 2015.

CAGLIARI, L. C. A escrita. In: Alfabetização e linguística. 6. ed. São Paulo: Editora Scipione, 1993. p. 95-116.

CONVENÇÃO para a grafia dos nomes tribais. Revista de Antropologia, São Paulo, v. 2, n. 2, p. 150-152, 1954.

FRANCÊS JÚNIOR, C. Atitude linguística e revitalização da língua Mundurukú: Observações preliminares. Belém. 2014. 107 f. Dissertação (Mestrado) - Programa de Pós-Graduação em Letras, Universidade Federal do Pará, Belém, 2014.

GALUCIO, A. V. (Org.). Narrativas tradicionais Sakurabiat mãyap ebõ. Belém: Museu Paraense Emílio Goeldi, 2006.

GALUCIO, A. V. Fonologia Segmental da Língua Mekens. In: IX encontro nacional da ANPOLL, 1994, Caxambu. Anais do IX encontro nacional da ANPOLL - Linguística, Caxambu, v. 2, p. 988-997, 1994.

GALUCIO, A. V.; SAQUIRABIAR, O. F. Sakurabiat Erek Ninga: alfabetização na língua Sakurabiat (Mekens). Belém: MPEG, 2004.

GNERRE, M. Linguagem, escrita e poder. 3. ed. São Paulo: Livraria Martins Fontes, 1991.

LAMBERT, W. E. A social Psychology of Bilingualism. In: PAULSTON, C. B.; TUCKER, G. R. (Orgs). Sociolinguistics: the essential readings. Malden, MA: Blackwell Publishing, 2003 [1967].

MARCUSCHI, L. A. Oralidade e letramento. In: Da fala para a escrita: atividades de retextualização. São Paulo: Cortez, 2001. p. 15-43.

MORENOFERNÁNDEZ, F. Actitudes linguísticas. In: Princípiosdesociolinguística y sociologia del lenguaje. 4. ed. Barcelona: Ariel, 1998. p. 177-190.

SPINASSÉ, K. P. Os conceitos Língua Materna, Segunda Língua e Língua Estrangeira e os falantes de línguas alóctones minoritárias no Sul do Brasil.

Revista Contingentia, Porto Alegre, v. 1, n. 1, p. 1-8, nov., 2006. 